\title{
The Possibility of Using Slag for the Production of Geopolymer Materials and Its Influence on Mechanical Performances-A Review ${ }^{\dagger}$
}

\author{
Brăduț Alexandru Ionescu *, Adrian-Victor Lăzărescu (1) and Andreea Hegyi \\ NIRD URBAN-INCERC Cluj-Napoca Branch, 117 Calea Florești, 400524 Cluj-Napoca, Romania; \\ adrian.lazarescu@incerc-cluj.ro (A.-V.L.); andreea.hegyi@incerc-cluj.ro (A.H.) \\ * Correspondence: bradut.ionescu@incerc-cluj.ro \\ † Presented at the 14th International Conference on Interdisciplinarity in Engineering-INTER-ENG 2020, \\ Târgu Mureș, Romania, 8-9 October 2020.
}

Published: 17 December 2020

\begin{abstract}
All industries produce wastes or byproducts, and if those are not properly managed, they will cause adverse effects on the environment. As the need for steel increases globally, waste from steel processing will also increase. Hazardous waste from steel processing is produced in the form of a coarse, dense aggregate, called steel slag. The aim of this paper is to present the possibility of using steel slag/blast furnace slag in the production of geopolymer concrete and to present the relevant results regarding the influence of this industrial byproduct on the mechanical properties of Geopolymer materials.
\end{abstract}

Keywords: geopolymer binders; industrial byproducts; sustainable development

\section{Introduction}

Industrial wastes generated by the various industries are a global problem with multiple social, financial and environmental effects. The efficient recycling of wastes and industrial byproducts is more than necessary in order to mitigate their negative effects, to reduce the consumption of other raw materials and to minimize at much as possible greenhouse gas emissions. Construction and demolition waste, fly ash, furnace/steel slag and mining waste can be recycled for reuse and to produce new, innovative materials in the civil engineering industry. Cement production raises major problems around the world through $\mathrm{CO}_{2}$ pollution of the atmosphere. Cement production is considered to have a global pollution share of $5-8 \%$ by total emissions of $\mathrm{CO}_{2}$ released into the atmosphere.

To reduce the high amount of carbon dioxide emissions released into the atmosphere during the production of Portland cement, alternative materials such as alkali-activated composites, or geopolymers, could provide a sustainable and durable approach. The most used raw materials in the production of alkali-activated geopolymer materials are fly ash and furnace/steel slag. Given the fact that the industries that produce these types of wastes are constantly growing, using these materials as raw materials offers the premises for producing alternative materials. As the need for steel increases globally, the waste produced by the steel processing industry will also increase. Hazardous waste from steel processing is produced in the form of a coarse, dense aggregate, called steel slag [1].

In 1999, Palomo proposed the possibility of activating puzzolanic materials such as furnace slag and fly ash "using alkaline liquids, to form a binder and completely replace the use of Portland cement in the production of concrete" [2]. Geopolymer concrete, known as alkali-activated cement [3], inorganic polymer concrete [4] or geocement [5], has emerged as an innovative way of new engineering materials, entirely replacing traditional Portland cement. In order to successfully produce geopolymer 
materials, the raw materials used in their production have to be rich in silicon ( $\mathrm{Si}$ ) and aluminum ( $\mathrm{Al})$. Due to the chemical composition of the raw materials, geopolymers incorporating significant amounts of calcium-rich materials, such as slag, for example, may have different properties than those based only on low-calcium fly ash.

The industrial use of waste in the production of geopolymer concrete will not only have economic and environmental benefits but will also solve the problems associated with the removal of large amounts of waste materials, such as coal-fired power plant ash and slag from the production of metals, which otherwise could endanger the environment. Using different types of slag to produce alkali-activated geopolymer biners is important not only for saving metal resources but also for protecting the environment.

The aim of this paper is to present the relevant results from the literature on the influence of the use of this industrial byproduct on the mechanical properties of geopolymer materials and also the possibility of using steel slag/blast furnace slag in the production of geopolymer concrete, without the use of Portland cement. Studying the mechanisms that affect the properties of geopolymer materials, such as raw materials, mix-design ratio, testing procedures, etc., represents the current methodology of this study.

\section{Results and Discussions}

Slag is a byproduct obtained during the manufacture of cast iron and steel. Various slags are produced as byproducts in metallurgical processes or as residues in incineration processes [6]. Blast Furnace Slag (BFS) is a non-metallic (oxidic) byproduct, resulting from the process of obtaining cast iron in furnaces, where the melting of iron mixed with coke and fondants (for example dolomite) takes place [7]. In the furnace crucible, cast iron is obtained at the bottom and slag at the top. The emission of steel slag makes up $13-20 \%$ of steel production [8]. Steel Slag (SS) results from the process of obtaining steel by different processes: Martin furnace, converter, electric furnace. Ground Granulated Blast Furnace Slag (GGBFS) is a fine granular material, resulting from the cooling of the blast furnace in a lot of water. GBBS has a high hydraulic activity potential and can be easily used in the preparation of geopolymer materials [9-11].

This industrial waste contains calcium, magnesium, manganese and aluminum silicates in various combinations along with iron oxide. The major difference between blast furnace slag and steel slag is the iron content [6-8]. For blast furnace slag, the FeO content is about $0.5 \%$, while in the case of steel slag, the total iron content varies from 16 to $23 \%$ [12]. Chemical composition is an important parameter when producing alkali-activated materials. Depending on the raw materials used in the metallurgical industry, slag composition could vary drastically. These differences in raw materials lead to differences in how slag responds to alkaline activation [13,14].

In the case of slag blended systems, the geopolymerization reaction rate generally increases with higher amounts of slag and at higher activator amounts [15-17]. Although the good properties of alkali-activated slag-based geopolymer materials have been demonstrated, when using these types of blended systems, several parameters, such as workability, including relatively rapid slump loss, could become a major concern $[8,15,16]$.

According to Shi Qian [18], the principle of alkali-activation of furnace slag has been known since the 1940s, when Purdon published several studies regarding the use of this raw material in the production of alkali-activated geopolymer [19]. However, it was only in the 1960s that systematic exploratory studies on this topic were conducted, especially by Gluhovsky and Pakhovmov. Industrial applications include 9-storey buildings ( 1960), 20-storey buildings ( 1987), sewer pipes ( 1966), irrigation canals $(\sim 1962)$, road sidewalk $(\sim 1984)$, railway sleepers $(\sim 1989)$ as well as fire doors ( 2000) [20].

Most of the research regarding the use of slag in the production of alkali-activated geopolymer material refer to fly ash-blast furnace slag/steel slag blended systems in various mixtures, with or without heat treatment [15-17]. Moreover, research includes most of the time results regarding 
compressive strength under conditions of chemical attack (sulfuric acid, sodium sulfate and sodium chloride) [21-27].

$\mathrm{Ng}$ and Foster [28] reported that for the production of slag-fly ash-based geopolymer systems, the mass ratio between them varies according to the reactivity of the fly ash and slag. These parameters are important in order to obtain an optimum compressive strength of the material.

The properties of alkali-activated geopolymer materials depend mainly on the important factors that could affect the development of this type of material and include the characteristics of constituent materials. The mechanical properties of the geopolymer materials are directly affected by the way in which the rich Al-Si materials dissolve in the alkaline activator and their microstructural reorganization when the reaction occurs [29-31].

In practice, on a case-by-case basis, an analysis is required regarding the chemical composition of the byproducts used as raw materials in the production of geopolymer material $[6-8,29,30]$. Studies conducted worldwide show that the chemical composition of the raw materials used in the production of geopolymer materials has an important influence on the final mechanical properties of the material.

Table 1 summarizes the chemical composition of fly ash and blast furnace slag/steel slag, according to different authors, used for the production of these materials. It can be seen in the table below that $\mathrm{Fe}_{2} \mathrm{O}_{3}$ is higher for fly ash. Moreover, it is noted that for steel slag, $\mathrm{FeO}$ has a very high percentage, between $10-40 \%$, compared to furnace slag $0.26-1.1 \%$.

Table 1. Chemical composition of raw materials used in the production of alkali-activated geopolymer materials, measured by $\mathrm{X}$-ray fluorescence [wt $\%]$.

\begin{tabular}{|c|c|c|c|c|c|c|c|c|}
\hline Oxide & $\mathrm{SiO}_{2}$ & $\mathrm{Al}_{2} \mathrm{O}_{3}$ & $\mathrm{Fe}_{2} \mathrm{O}_{3}$ & $\mathrm{CaO}$ & $\mathrm{MgO}$ & $\mathrm{SO}_{3}$ & L.O.I. & Ref. \\
\hline Fly Ash & 21.94 & 8.46 & 6.05 & 45.4 & 6.06 & 0 & 6.65 & \multirow{2}{*}{ [21] } \\
\hline Blast furnace slag & 37.33 & 12.49 & 0.26 & 43.3 & 5.31 & 0 & 0 & \\
\hline Fly Ash & 65.81 & 22.17 & 3.23 & 1.24 & 1.01 & 0.47 & 1.57 & \multirow{2}{*}{ [22] } \\
\hline Slag & 37.25 & 10.24 & 1.1 & 42.17 & 3.82 & 2.13 & 0.81 & \\
\hline Fly Ash & 52.0 & 33.9 & 4.0 & 1.2 & 0.81 & 0.28 & 6.23 & \multirow{2}{*}{ [23] } \\
\hline Steel Slag & $10-19$ & $1-3$ & $10-40(\mathrm{FeO})$ & $40-52$ & $5-10$ & - & & \\
\hline Fly Ash & 61.81 & 19.54 & 7.01 & 1.77 & 2.56 & 0.31 & 2.20 & \multirow{2}{*}{ [24] } \\
\hline $\begin{array}{l}\text { Ground Granulated } \\
\text { Blast Furnace Slag }\end{array}$ & 36.7 & 5.20 & 0.98 & 32.61 & 10.12 & 0.99 & 2.88 & \\
\hline Fly ash & 51.11 & 25.56 & 12.48 & 4.3 & 1.45 & 0.24 & 0.57 & \multirow{2}{*}{ [25] } \\
\hline Slag & 32.76 & 12.37 & 0.54 & 44.64 & 5.15 & 4.26 & 0.09 & \\
\hline Fly Ash & 63.53 & 27.40 & 3.67 & 1.26 & 0.35 & 0.01 & - & \multirow{2}{*}{ [26] } \\
\hline Slag & 34.26 & 11.32 & 0.61 & 38.34 & 7.94 & 3.84 & - & \\
\hline Fly Ash & 48.3 & 28.3 & 11.8 & 3.97 & 1.51 & 0.22 & 1.74 & \multirow{2}{*}{ [27] } \\
\hline Slag & 32.9 & 14.3 & 0.47 & 41.2 & 5.42 & 2.40 & 0.36 & \\
\hline
\end{tabular}

When using slag-fly ash blended systems, an increased amount of fly ash delays the setting time, reduces the compressive strength modulus of elasticity and Poisson's ratio and results in high ductility and toughness $[16,32,33]$ but helps the geopolymer system to have an enhanced homogeneity and also contributes to a limited microcracking phenomenon [33].

The summarized details presented in Table 1 of several raw materials used in the literature to produce alkali-activated geopolymer materials show that due to their different chemical composition, this parameter needs to be carefully taken into account as it could provide a guide line to evaluate later possible reactions and outputs for the improvement of the mechanical properties of the final material.

To attain a similar or even higher compressive strength when compared to OPC concrete, geopolymer materials require heat treatment. This type of curing process is beneficial for the dissolution and geopolymerization process of the aluminosilicate gel and also results in early-age strength gain of the material [34-36]. As shown in the literature, adopting the proper curing treatment 
for the production of alkali-activated geopolymer materials must be appropriate in order to provide an ideal condition for the dissolution and precipitation of dissolved silica and alumina species [34].

\subsection{Development of Geopolymer Materials without Heat Treatment}

It is well known that typical fly ash-based geopolymer concrete requires high temperature curing treatment in order to develop sufficient early mechanical strength properties, which can be considered a severe limitation for on-site applications. However, in recent years, methods of producing geopolymer concrete without using heat treatment have been exploited. In order to achieve this, extensive experimental investigation on the mechanical and microstructural properties of geopolymer concrete mixes prepared using a combination of fly ash and slag and cured under ambient temperature to produce "user-friendly" geopolymer mixes have been researched.

Hyumjung et Yooteak (2012) [21] carried out tests regarding the mechanical properties of alkali-activated geopolymer concrete, without heat treatment by using as binder, a combination between fly ash and blast furnace slag, in different ratios. It can be seen in Table 2 that the compressive strength increased with the increase in the percentage of furnace slag in the mix-design of the geopolymer. The highest compressive strength was achieved for a geopolymer mortar produced only by using blast furnace slag, without fly ash (44 MPa—at 28 days), almost double that of a geopolymer mortar produced using blast furnace slag-fly ash with a 50:50 ratio.

Table 2. Geopolymer mortar compressive strength of, without heat treatment, depending on the fly ash/blast furnace slag ratio [21].

\begin{tabular}{ccccc}
\hline Mixture & FA/BFS Ratio & $\begin{array}{c}\text { Compressive Strength } \\
\text { [MPa] }\end{array}$ & Binder/Water Ratio & NaOH Molarity \\
\hline I & $100: 0$ & 2.81 & & \\
II & $50: 50$ & 23.51 & $100: 40$ & 2.78 \\
III & $0: 100$ & 44.41 & & \\
\hline
\end{tabular}

Luga et al. (2017) [24] also presented the compressive strength obtained for geopolymer materials using a fly ash-ground granulated blast furnace slag binding system, without heat treatment. Results are presented in Table 3.

Table 3. Geopolymer mortar compressive strength, without heat treatment, depending on the fly ash/ground granulated blast furnace slag ratio [24].

\begin{tabular}{ccc}
\hline Mixture & FA/GGBFS Ratio & $\begin{array}{c}\text { Compressive Strength at 28 Days } \\
\text { [MPa] }\end{array}$ \\
\hline I & $100: 0$ & 3.1 \\
II & $80: 20$ & 8.4 \\
III & $60: 40$ & 18.2 \\
IV & $40: 60$ & 39.3 \\
V & $20: 80$ & 57.6 \\
VI & $0: 100$ & 74.8 \\
\hline
\end{tabular}

It can be also seen in Table 3 that the compressive strength increased with the increase in the percentage of furnace slag in the mix-design of the geopolymer. The highest compressive strength was achieved for a geopolymer mortar produced only by using blast furnace slag, which also confirms previous studies in the field.

Other studies show that Steel Slag can be also used as addition to fly ash in order to produce the alkali-activated geopolymer binder. Premalta (2017) [23] also presented the results obtained regarding the compressive strength of a geopolymer concrete with steel slag addition between $2 \div 3.5 \%$, at different ages. According to the data in the Table 4, it is observed that the compressive strength of 
geopolymer concrete increased to a percentage of $2.5 \%$ steel slag, after which it decreases, showing that the behavior of the geopolymer binder should be analyzed on a case-by-case situation.

Table 4. Compressive strength at different ages and different percentages of steel slag addition [23].

\begin{tabular}{cccccc}
\hline \multirow{2}{*}{ Mixture } & $\begin{array}{c}\text { Steel Slag } \\
{[\%]}\end{array}$ & \multicolumn{4}{c}{$\begin{array}{c}\text { Compressive Strength } \\
\text { [MPa] }\end{array}$} \\
\cline { 3 - 6 } & & 2 Days & 7 Days & 14 Days & 28 Days \\
\hline I & 2.0 & 3.5 & 8.5 & 13.3 & 21.3 \\
II & 2.5 & 4.8 & 9.3 & 14.7 & 23.9 \\
III & 3.0 & 3.3 & 7.8 & 12.9 & 18.6 \\
IV & 3.5 & 3.6 & 7.2 & 11.9 & 16.6 \\
\hline
\end{tabular}

In another study, Nematollahi (2017) [25] presented the results regarding the compressive strength obtained for a fly ash-blast furnace slag-based geopolymer material with a constant ratio FA:BFS of 75:25 and different activator ratios, cured at ambient temperature. As shown in Table 5, it is noted that the compressive strength increases with the increase in the alkali-activator chemical properties, which also demonstrates that the chemical composition of the raw material is only one of the important parameters that affect the mechanical properties of the material. Careful selection of the alkali-activator and the ratio of the component materials should be taken into account.

Table 5. Compressive strength of non-heat-treated FA-BFS Geopolymers [25].

\begin{tabular}{cccccc}
\hline Mixture & FA:BFS & $\begin{array}{c}\mathbf{N a}_{2} \mathrm{SiO}_{3} \text {-Anhydrous } \\
\text { Activator }\end{array}$ & Water & W/GP Solid Ratio & $\begin{array}{c}\text { Compressive Strength } \\
\text { [MPa] }\end{array}$ \\
\hline I & & & 0.394 & 0.36 & 18.4 \\
II & $75: 25$ & 0.120 & 0.400 & 0.36 & 30.5 \\
III & & & 0.300 & 0.27 & 37.3 \\
\hline
\end{tabular}

\subsection{Development of Geopolymer Materials with Heat Treatment}

The effect of the curring temperature on the alkali-activated geopolymer materials has been demonstrated by numerous studies which have shown that by using this type of treatment, improvements were observed in the geopolymerization reaction and also increases in the mechanical properties of the material, at very young ages [29,30,37].

Puertas et al. investigated the mechanical properties of alkali-activated fly ash/slag-based geopolymers by using as alkaline activator a combination between $\mathrm{Na}_{2} \mathrm{SiO}_{3}$ solution and $\mathrm{NaOH}$ solution with 2 and $10 \mathrm{M}$ molarity and subjected to heat treatment at 25 and $65{ }^{\circ} \mathrm{C}$. According to the results, the ratios of fly ash/slag and of activator are the most important factors that influence the mechanical performance of the material since the hardening temperature has less effects compared to the two previous factors [38].

In another study, Ghosh and Ghosh (2018) [22] made different tests on geopolymers produced using fly ash and ground granulated blast furnace slag (GGBFS) as raw materials in different ratios: 100:0, 90:10, 85:15, 70:30, 50:50, 40:60. Geopolymers were subjected to heat treatment for $48 \mathrm{~h}$, at a temperature of $85^{\circ} \mathrm{C}$. The samples were tested after 7 days.

As shown in Figure 1, the compressive strength of the mixtures increased with the addition of slag content. There was an increase in the compressive strength of the $90: 10$ mixtures by $19.99 \%$ over the 100:0 mixtures. Moreover, the compressive strength of the $85: 15$ mixture was $15.97 \%$ higher compared to the 90:10 mixture. The 70:30 mixtures showed an increase in compressive strength of $14.75 \%$ over the $85: 15$ mixtures. The highest compressive strength was obtained for the 70:30 mixtures. 
Compressive strength for different FA:GGBFS ratios

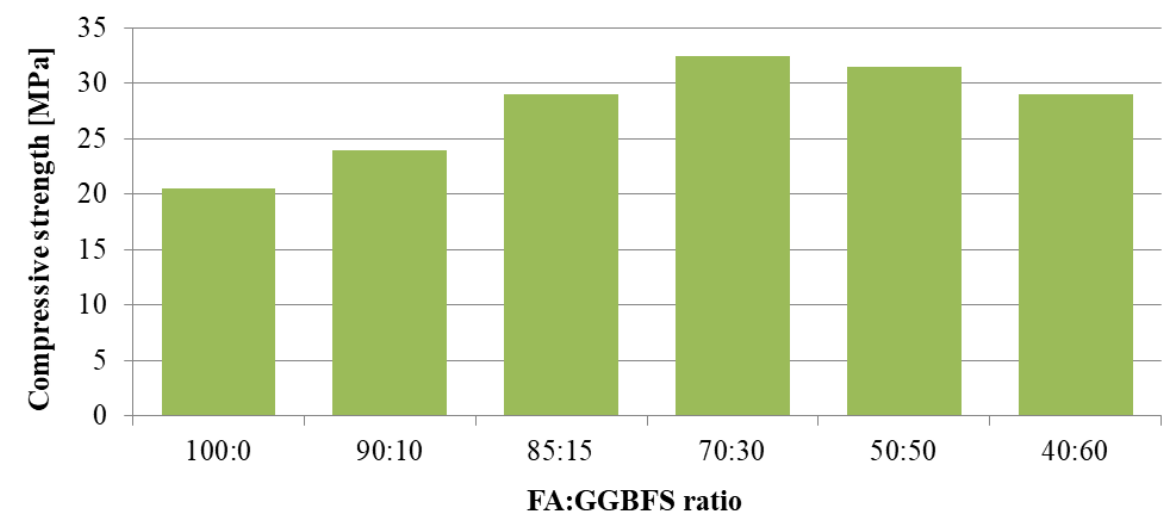

Figure 1. Effect of slag ratio variation on the compressive strength of the geopolymer material [22].

Decreases of $3.43 \%$ and $6.33 \%$ in the compressive strength were also observed for the 50:50 and 40:60 mixtures when compared to the 70:30 mixtures and the 50:50 mixtures, respectively. This phenomenon could be a sign of a low geopolymerization process; therefore, lower mechanical properties have been achieved.

Luga et al. (2017) [24] presented the compressive strength of a geopolymer mortar based on fly ash and granulated blast furnace slag (GGBFS), with a heat treatment of $72 \mathrm{~h}$ at a temperature of $100^{\circ} \mathrm{C}$. Results presented in Table 6 regarding the compressive strength of the alkali-activated geopolymer material are in accordance with the literature [22,39] showing that with the increase in the GGBF content in the mixture, the compressive strength of the material increased.

Table 6. The effect of the variation of the compressive strength of some geopolymers mortars based on fly ash and ground granulated blast furnace slag, with heat treatment $\left(72 \mathrm{~h} / 100^{\circ} \mathrm{C}\right)$ [24].

\begin{tabular}{ccc}
\hline Mixture & FA/GGBFS Ratio & Compressive Strength [MPa] \\
\hline I & $100: 0$ & 15.4 \\
II & $80: 20$ & 13.7 \\
III & $60: 40$ & 12.1 \\
IV & $40: 60$ & 46.6 \\
V & $20: 80$ & 45.7 \\
VI & $0: 100$ & 42.7 \\
\hline
\end{tabular}

Based on the results presented above, it can be said that the curring temperature is one of the most important factors affecting the mechanical properties of alkali-activated geopolymer materials when subjected to this type of treatment. For the heat curring regimes, there are a lot of possibilities both for their duration and temperature in order to achieve the desired mechanical properties of the geopolymer material.

\subsection{Development of Geopolymer Materials with High Chemical Attack Properties}

Kartik et al. (2017) [26] studied the resistance of geopolymers based on coal fly ash and blast furnace slag after the test pieces were exposed to an acidic medium ( $5 \%$ sulfuric acid) for $7,14,28$, 56 and 90 days, respectively, to a sodium sulphate attack and sodium chloride.

It can be seen in Figure 2a that the compressive strength decreases with the increase in the duration of immersion in sulfuric acid. The decrease in compressive strength is not significant given the extreme aggressive environment and the long immersion duration of 90 days. For the geopolymers GPC1, GPC2 and GPC 3 there was a decrease of only $3-4 \mathrm{MPa}$, about $10 \%$. For GPC 0 there was a considerable decrease in compressive strength, from $28 \mathrm{MPa}$ to $18 \mathrm{MPa}$, almost $34 \%$. 


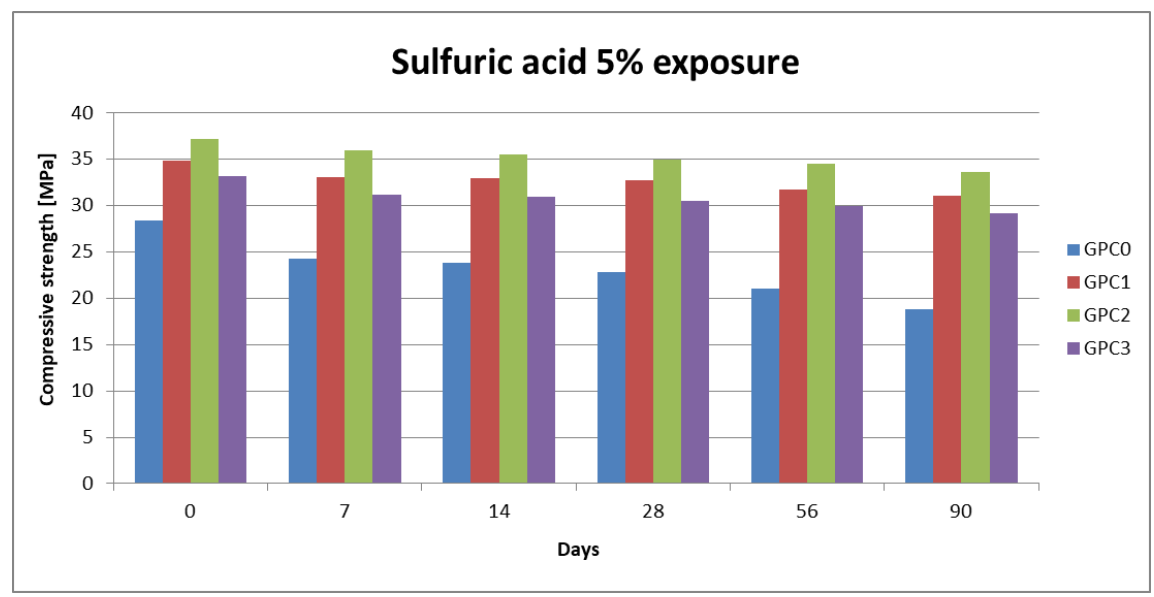

(a)

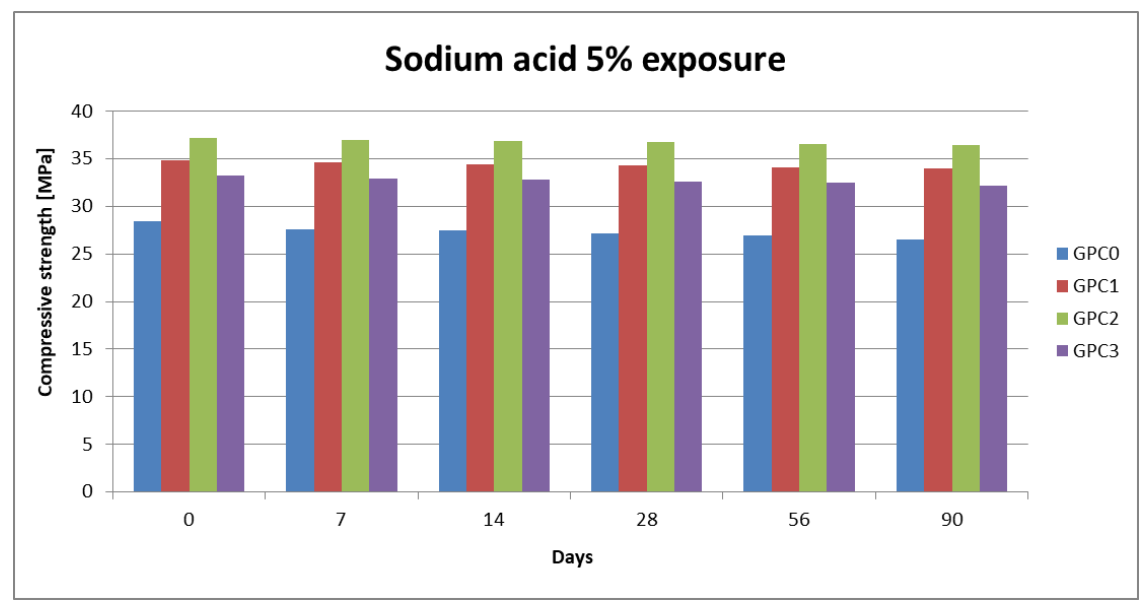

(b)

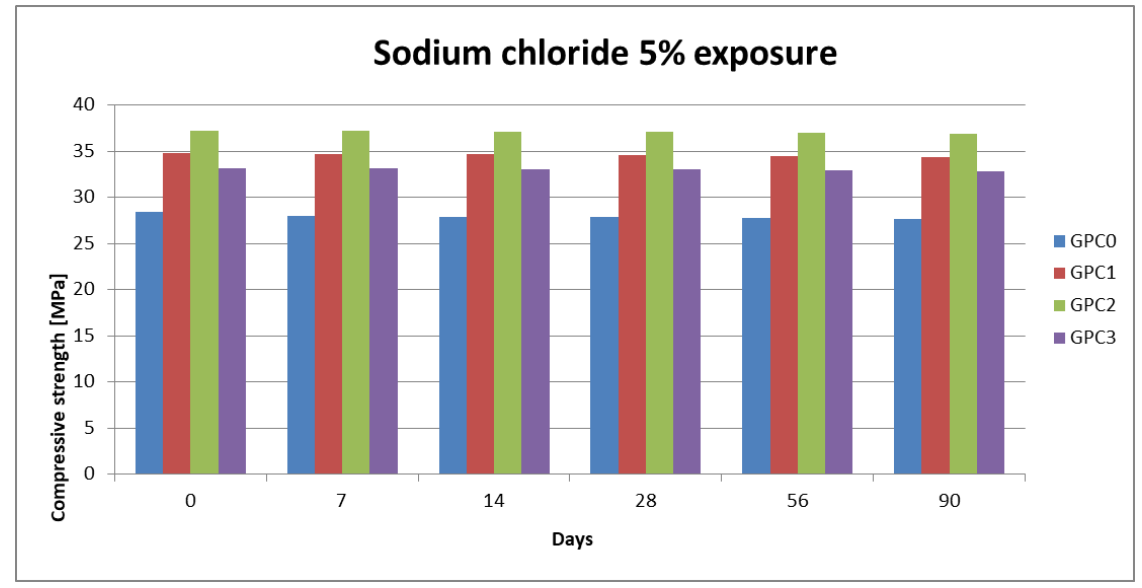

(c)

Figure 2. Geopolymer materials compressive strength when exposed to chemical attack: (a) sulfuric acid exposure; (b) sodium acid exposure; (c) sodium chloride exposure.

Moreover, Kartik et al. (2017) studied the behavior of geopolymers compression, after having previously been subjected to an attack with sodium sulfate $5 \%$ (Figure $2 b$ ) and sodium chloride $5 \%$ (Figure 2c), respectively. 
After long-time exposure to a sodium sulphate attack, the compressive strength decreased over time (Figure 2b). In comparison with the test pieces subjected to sulfuric acid immersion, those immersed in sodium sulphate showed better results. For the geopolymer GPC0, the lowest resistances and the greatest resistance decrease were obtained, as well as those immersed in sulfuric acid. If for the Geopolymers GPC1, GPC2, GPC3 were obtained decreases of 3-4 MPa (approx. 10\%) for samples immersed in sulfuric acid, for those subjected to attack with sodium sulfate were obtained decreases of approx. $1 \mathrm{MPa}$ (approx. 2.5\%). Specimens long exposed for 90 days to a 5\% sodium chloride attack suffered the least. They showed the lowest losses of compressive strength, i.e., approx. $1 \%$.

\section{Conclusions}

Geopolymer technology is gaining quite a lot of ground due to the successful implementation of this type of material in certain countries, in different areas. This aspect is mainly due to the need to align with the principles of the circular economy by harnessing waste materials and byproducts and to also prevent generating new ones. The possibility of producing geopolymer building materials using slag as raw material was demonstrated, but only by compositional optimization due to the multitude of influences affecting this type of material.

Geopolymers materials have shown better properties when subjected to heat treatments to (accelerated) heat hardening, since geopolymerization and polycondensation reactions would occur faster. Moreover, the addition of slag at an optimum level of 30\% increased the mechanical properties of heat-treated geopolymer composites, e.g., increasing compressive strength.

Studies have also shown that fly ash-slag based geopolymer materials have a very good resistance to chemical attacks (sulfuric acid, sodium sulphate or sodium chloride) over a long period.

Therefore, producing geopolymer concrete based on blast furnace slag/steel slag and fly ash will lead to long-term environmental protection, obtaining very good compressive strength from an early age and is an alternative to traditional concrete based on Portland cement in the future.

The need to continue existing studies is identified due to the many unknowns in the field regarding the geopolymerization process and the properties of the geopolymer concrete as well as the products derived from this process when using different raw materials to produce the geopolymer binder. Thus, the approach of this research direction falls within the current complex theme, aligned to worldwide research on innovative ways of harnessing byproducts or wastes in the development of new building materials.

Funding: This research received no external funding.

Conflicts of Interest: The authors declare no conflict of interest.

\section{References}

1. Ashadi, H.W.; Aprilando, B.A.; Astutiningsih, S. Effects of Steel Slag Substitution in Geopolymer Concrete on Compressive Strength and Corrosion Rate of Steel Reinforcement in Seawater and an Acid Rain Enviroment. Int. J. Technol. 2015, 2, 227-235. [CrossRef]

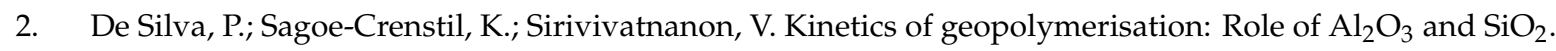
Cem. Conc. Res. 2007, 37, 512-518. [CrossRef]

3. Bosoaga Masek, O.; Oakey, J.E. $\mathrm{CO}_{2}$ capture technologies for cement Industry, Energy. Procedia 2009, 1, 133-140.

4. Barcelo, L.; Kline, J.; Walenta, G.; Gartner, E. Cement and carbon emissions. Mater. Struct. 2014, 47, $1055-1065$. [CrossRef]

5. Duxson, P.; Provis, J.L.; Lukey, G.C.; van Deventer, J.S.J. The role of inorganic polymer technology in the development of 'green concrete'. Cem. Concr. Res. 2007, 37, 1590-1597. [CrossRef]

6. Shen, H.; Forssberg, E. An Overview of Recovery of Metals from Slags. Waste Manag. 2003, 23, $933-949$. [CrossRef] 
7. Liu, J.; Dongmin, W. Application of Ground Granulate Blast FurnaceSlag-Steel Slag Composite Binder in a Massive ConcreteStructure under Severe Sulphate Attack. Adv. Mater. Sci. Eng. 2017, 2017, 9493043. [CrossRef]

8. Furlani, E.; Tonello, G.; Maschio, S. Recycling of steelslag and glass cullet from energy saving lamps by fast firingproduction of ceramics. Waste Manag. 2010, 30, 1714-1719. [CrossRef]

9. El-Sayed, H.A.; El-Enein, S.A.A.; Khater, H.M.; Hasanein, S.A. Resistance of alkali activated water-cooled slag geopolymer to sulphate attack. Ceram Silik. 2011, 55, 153-160.

10. Yang, H.F.; Dang, C.G.; Xu, W. Preparation of geopolymer using the slag from direct reduction-magnetic separation of refractory iron ore (SDRMS). Manuf. Sci. Technol. 2012, 383, 911-915. [CrossRef]

11. Kashani, A.; Provis, J.L.; van Deventer, J.S.J. Effect of ground granulated blast furnace slag particle size distribution on paste rheology: A preliminary model. AIP Conf. Proc. 2013, 1542, 1094-1097.

12. Indian Minerals Yearbook 2012 Part- II: Metals E Alloys, 51st Edition, Slag-Iron and Steel; Government of India, Ministry of Mines, Indian Bureau of Mines: Nagpur, India, 2012.

13. Bakharev, T.; Sanjayan, J.G.; Cheng, Y.-B. Effect of elevated temperature curing on properties of alkali-activated slag concrete. Cem. Concr. Res. 1999, 29, 1619-1625. [CrossRef]

14. Wang, S.-D.; Scrivener, K.L.; Pratt, P.L. Factors affecting the strength of alkali-activated slag. Cem. Concr. Res. 1994, 24, 1033-1043. [CrossRef]

15. Bijen, J. Benefits of slag and fly ash. Construct. Build. Mater. 1996, 10, 309-314. [CrossRef]

16. Nath, P.; Sarker, P.K. Effect of GGBFS on setting, workability and earlystrength properties of fly ash geopolymer concrete cured in ambient condition. Construct. Build. Mater. 2014, 66, 163-171. [CrossRef]

17. Provis, J.L. Geopolymers and other alkali activated materials: Why, how, and what? Mater. Struct. 2014, 47, 11-25. [CrossRef]

18. Shi, C.; Qian, J. High Performance Cementing Materials from Industrial slags-A review. Resour. Conserv. Recycl. 1999, 29, 195-207. [CrossRef]

19. Purdon, A.O. The action of alkalis on blast furnace slag. J. Soc. Chem. Ind. 1940, 59, 191-202.

20. Recommended Practice- Geopolymer Concrete 2011; Concrete Institute of Australia: Sydney, Australia, 2011.

21. Kim, H.; Kim, Y. Characteristics of the Geopolymer using Fly Ash and Blast Furnace Slag with Alkaline Activators. In Proceedings of the 4th International Conference on Chemical, Biological and Environmental Engineering, Phket, Thailand, 1-2 September 2012; IPCBEE: Singapore, 2012; Volume 43, pp. 154-159.

22. Ghosh, K.; Ghosh, P. Effect of variation of slag content on chemical, engineering and microstructural properties of thermally cured fly ash-slag based geopolymer composites. Rasayan J. Chem. 2018, 11, 426-439.

23. Premalatha, P.V.; Rhema Rose, C.; Aboorvaraj, K.A. A Comparison of Geopolymer Concrete Blended with Steel Slag under Sunlight and Ambient Curing. AJAST 2018, 2, 55-62.

24. Luga, E.; Atis, D.C.; Karahan, O.; Ilkentapar, S.; Gorur, E.B. Strength properties of slag/fly ash blends activated with sodium metasilicate. GRAĐEVINAR 2017, 69, 199-205.

25. Nematollahi, B. Investigation of Geopolymer as a Sustainable Alternative Binder for Fiber-Reinforced Strain-Hardening Composites. Ph.D. Thesis, Faculty of Science, Engineering and Technology, Swinburne University of Technoogy, Hawthorn, Australia, 2017.

26. Karthik, A.; Sudalaimani, K.; Vijayakumar, C.T. Durability study on coal fly ash-blast furnace slag geopolymer concretes with bio-additives. Ceram. Int. 2017, 43, 11935-11943. [CrossRef]

27. Neupane, K.; Sriravindrarajah, R.; Baweja, D.; Des Chalmers, I. Effect of curing on the compressive strength development in structural grades of geocement concrete. Construct. Build. Mater. 2015, 94, 241-248. [CrossRef]

28. Hassan, A.; Arif, M.; Shariq, M. Use of Geopolymer Concrete for a Cleaner and Sustainable Environment-A Review of Mechanical Properties and Microstructure. J. Clean. Prod. 2019, 223, 704-728. [CrossRef]

29. Lăzărescu, A.; Szilagyi, H.; Ioani, A.; Baeră, C. Parameters Affecting the Mechanical Properties of Fly Ash-Based Geopolymer Binders-Experimental Results. IOP Conf. Ser. Mater. Sci. Eng. 2018, 374, 012035. [CrossRef]

30. Lăzărescu, A.V.; Szilagyi, H.; Baeră, C.; Ioani, A. The Effect of Alkaline Activator Ratio on the Compressive Strength of Fly Ash-Based Geopolymer Paste. IOP Conf. Ser. Mater. Sci. Eng. 2017, 209, 012064. [CrossRef] 
31. Nergis, D.D.B.; Abdullah, M.M.A.; Sandu, A.V.; Vizureanu, P. XRD and TG-DTA study of new alkali activated materials based on fly ash with sand and glass powder. Materials 2020, 13, 343. [CrossRef]

32. Lee, N.; Lee, H. Setting and mechanical properties of alkali-activatedfly ash/slag concrete manufactured at room temperature. Construct. Build. Mater. 2013, 47, 1201-1209. [CrossRef]

33. Lee, N.; Lee, H. Reactivity and reaction products of alkali-activated, fly ash/slag paste. Construct. Build. Mater. 2015, 81, 303-312. [CrossRef]

34. Diaz, E.I.; Allouche, E.N.; Eklund, S. Factors affecting the suitability of fly ash as source material for geopolymers. Fuel 2010, 89, 992-996. [CrossRef]

35. Fernandez-Jimenez, A.; Palomo, A.; Sobrados, I.; Sanz, J. The role played by the reactive alumina content in the alkaline activation of fly ashes. Micoporous Mesoporous. Materials 2006, 91, 111-119.

36. Khale, D.; Chauldhary, R. Mechanism of geopolymerization and factors influencing its deveolpment: A review. J. Mater. Sci. 2007, 42, 729-746. [CrossRef]

37. Dutta, D.; Chakrabarty, S.; Bose, C.; Ghosh, S. Evaluation of geopolymer properties with temperature imposed on activator prior mixing with fly ash. Int. J. Civ. Eng. 2012, 3, 205-213.

38. Puertas, F.; Martinez-Ramirez, S.; Alonso, S.; Vazquez, T. Alkali-Activated Fly Ash/Slag Cement Strength Behaviour, Hydration Products. Cem. Concr. Res. 2000, 30, 1625-1632. [CrossRef]

39. Provis, J.L.; Myers, R.J.; White, C.E.; Rose, V.; van Deventer, J.S.J. X-ray microtomography shows pore structure and tortuosity in alkali-activated binders. Cem. Concr. Res. 2012, 42, 855-864. [CrossRef]

Publisher's Note: MDPI stays neutral with regard to jurisdictional claims in published maps and institutional affiliations. 